\title{
Laparoscopic and open resection of rectal cancer-is age an effect modifier for short- and long-term survival?
}

\author{
Teresa Draeger $^{1}$ (D) Vinzenz Völkel ${ }^{1} \cdot$ Valentin Schnitzbauer $^{2} \cdot$ Michael Gerken $^{1} \cdot$ Stefan Benz $^{3}$. \\ Monika Klinkhammer-Schalke ${ }^{1}$ • Alois Fürst ${ }^{4}$
}

Accepted: 6 February 2019 / Published online: 18 February 2019

(C) The Author(s) 2019

\begin{abstract}
Introduction Rectal cancer is a frequently diagnosed tumor worldwide. Various studies have shown the noninferiority or even slight superiority of laparoscopic resection. However, there is no clear recommendation on whether age should influence the choice of surgical approach.

Materials and methods This study compared outcomes of laparoscopic and open surgery in rectal cancer patients. Perioperative mortality and 5-year overall, relative, and recurrence-free survival rates were analyzed separately for three age groups. Data originate from 30 regional German cancer registries that cover approximately one quarter of the German population. All primary nonmetastatic rectal adenocarcinoma cases with surgery between 2005 and 2014 were eligible for inclusion. To compare survival rates, Kaplan-Meier analysis, a relative survival model, and multivariable Cox regression were used; a sensitivity analysis assessed bias by exclusion.

Results Ten thousand seven hundred fifty-four patients were included in the analysis. The mean laparoscopy rate was $23.0 \%$ and increased over time. Analysis of 30-day postoperative mortality rates revealed advantages for laparoscopically treated patients, although the significance level was not reached in any age group. Regarding 5-year overall survival, laparoscopy generally seems to be the superior approach, whereas for recurrence-free survival, an age-dependent gradient in effect size was observed: with a hazard ratio (HR) of 0.703 for laparoscopy, patients under 60 years benefitted more from the minimally invasive approach than older patients (septuagenarians, HR 0.923).

Conclusion Laparoscopy shows similar results to the open approach in terms of postoperative survival in all age groups. Concerning long-term outcomes, younger patients benefitted most from the minimally invasive approach.
\end{abstract}

Keywords Bowel cancer $\cdot$ Minimally invasive surgery $\cdot$ Age groups $\cdot$ Health services research $\cdot$ Registries

Teresa Draeger

teresa.draeger@gmx.de

1 Tumorzentrum Regensburg - Institut für Qualitätssicherung und Versorgungsforschung der Universität Regensburg, Am BioPark 9, 93053 Regensburg, Germany

2 Universität Regensburg, Universitätsstraße 31, 93053 Regensburg, Germany

3 Klinik für Allgemeine-, Viszeral- und Kinderchirurgie, Kliniken Böblingen, Bunsenstr. 120, 71032 Böblingen, Germany

4 Klinik für Allgemein-, Viszeral-, Thoraxchirurgie und Adipositasmedizin, Caritas Krankenhaus St. Josef Regensburg, Landshuter Str. 65, 93053 Regensburg, Germany

\section{Introduction}

Colorectal cancer ranks among the top three malignant tumor entities in Germany and worldwide [1]. According to a survey conducted by the World Health Organization (WHO), 1.4 million people worldwide were diagnosed with this type of tumor in 2012 [2]. Approximately one-third of these carcinomas are located in the rectum [1].

Curative treatment of colorectal carcinoma involves radical surgical resection of the tumor. In the past, open surgery was the first choice for rectal resections, and even today, many surgeons still prefer the conventional approach. Despite promising results in favor of the minimally invasive approach derived from the high-quality COLOR II trial published in 2015 [3], as well as those from a number of other important pro- and retrospective trials [4-7], there is an ongoing discussion on the topic [8]. 
The trend is moving increasingly toward individualized treatment pathways. It is not uncommon for benefits of a particular treatment to be associated with certain patient characteristics. Therefore, when assessing an intervention such as the surgical approach, it is necessary to conduct separate analyses for relevant subgroups. Age can have great influence on the perception of different therapeutic modalities [9]. Based on a large pooled database of German cancer registries, this study provides a comprehensive picture of short- and long-term survival after laparoscopic and open surgery with special emphasis on the influence of age.

In Germany, rectal cancer treatment is highly standardized by evidence-based guidelines and elaborate quality management processes [10-12], which aim to ensure a patient's adequate treatment regardless of social or economic status. Together with the huge study population of this survey allowing for detailed subgroup analyses, this guarantees ideal conditions to objectively examine oncologic outcomes after tumor resection in daily clinical practice.

\section{Patients and methods}

Data for this publication were gathered in 30 regional cancer registries located predominantly in southern and eastern Germany. Together, they cover approximately $28 \%$ of the entire German population. Each registry employs trained documentation officers who systematically collect medical records of all tumor patients registered in their area. For this purpose, all patients must provide their formal consent. Information on life status is regularly updated by official authorities or using death certificates issued by the public health service. The anonymized unified dataset of all 30 registries was prepared by data analysts of the German Cancer Registry Association (ADT) [13] in strict accordance with the organization's high data protection standards.

According to ICD-10-GM [14], all malignant tumors located $16 \mathrm{~cm}$ or less from the anocutaneous line are defined as rectal cancer (C20). For the purpose of this analysis, all patients up to the age of 79 years with a diagnosis of rectal cancer and surgery between January 1, 2005 and December 31, 2014 were eligible for inclusion. Subsequently, only patients with primary nonmetastatic adenocarcinomas and elective radical sphincter-preserving surgical treatment of their tumor were considered. Details on each patient include demographics, tumor characteristics, surgical procedure, and perioperative chemoradiotherapy (Table 1). For subgroup analyses, age at surgery was categorized into the following three groups: under 60 years, $60-69$ years, and $70-79$ years.

To compare 30-day postoperative mortality rates, uni- and multivariable logistic regression models were used. To determine the necessity of including each covariable in the multivariable model, an extensive literature search was first conducted. Thus, it was explored whether a variable has an independent influence on the outcome. Consequently, sex, tumor location, Union for International Cancer Control (UICC) stage, grading, and perioperative chemoradiotherapy were identified as potential confounders [15-21]. Second, a $\chi$ square distribution test was performed for the whole study population. All potential confounders with a probability of less than $p=0.5$ of being equally distributed in the open and laparoscopic surgery groups were included in the final model for the regression analyses.

Median follow-up was 6.2 years. Therefore, a 5-year observation period after surgery could be used to compare survival rates in patients with laparoscopic vs. open resections. To focus on the long-term perspective, the effect of perioperative mortality was eliminated by applying a 30-day cutoff time and $t=31$ days after surgery was set as the starting point for the observation period. Correspondingly, patients with a survival or observation time of less than 31 days were excluded from these analyses. In addition to Kaplan-Meier analysis, a multivariable Cox regression model was formulated [22]. Again, it was adjusted for all potential confounders that were unequally distributed in the open and laparoscopic surgery groups. To adjust for regional life expectancy, a relative survival model was computed [23]. Data on general mortality of the German population were obtained from the Human Mortality Database of the Max Planck Institutes [24].

To account for bias due to missing data, a sensitivity analysis was performed. This was based on univariable logistic regression and Kaplan-Meier analysis with inclusion of initially excluded patients. All significance tests were two sided with a significance level of 0.05 ; results are displayed as $p$ values or $95 \%$ confidence intervals (CI). The findings of this survey are presented in strict compliance with the Strengthening the Reporting of Observational studies in Epidemiology (STROBE) statement [25]. During this study, IBM SPSS 25 (IBM Corp., SPSS for Windows, Armonk, NY, USA), as well as R version 3.3.2 (R Foundation for Statistical Computing, Vienna, Austria; http://www.R-project.org/), and the R package "relsurv" (Maja Pohar-Perme) were used [23].

\section{Results}

From January 1, 2005 to December 31, 2014, 29,877 patients between 18 and 79 years of age underwent radical sphincterpreserving resection of a rectal carcinoma (ICD-10-GM: C20). At the time of surgery, $29.0 \%$ of these patients had already developed distant metastases, suffered from syn- or metachronous colorectal malignancies, had a tumor with uncommon histologic subtype, or underwent an emergency procedure. A further $18.2 \%$ of the patients lacked information on UICC TNM stage, grading, or tumor location, and in $16.9 \%$ of 
Table 1 Baseline characteristics of the study population according to surgical access. Lower third $\hat{=} 0-5.9 \mathrm{~cm}$, middle third $\stackrel{=}{=}-11.9 \mathrm{~cm}$, upper third $\stackrel{=}{ }$ $12-16 \mathrm{~cm}$ from anal verge

\begin{tabular}{|c|c|c|c|c|c|c|}
\hline \multirow[b]{2}{*}{ Sex } & \multirow{3}{*}{$\begin{array}{l}\text { Male } \\
\text { Female }\end{array}$} & \multicolumn{2}{|c|}{ Open $(n=8272)$} & \multicolumn{2}{|c|}{ Laparoscopic $(n=2743)$} & \multirow{3}{*}{$\frac{x^{2}}{<0.001}$} \\
\hline & & 5848 & $66.3 \%$ & 1508 & $61.0 \%$ & \\
\hline & & 2788 & $33.7 \%$ & 965 & $39.0 \%$ & \\
\hline \multirow[t]{3}{*}{ Age (years) } & $<60$ & 2137 & $25.8 \%$ & 819 & $33.1 \%$ & \multirow[t]{3}{*}{$<0.001$} \\
\hline & $60-69$ & 2837 & $34.3 \%$ & 839 & $33.9 \%$ & \\
\hline & $70-79$ & 3298 & $39.9 \%$ & 815 & $33.0 \%$ & \\
\hline \multirow[t]{3}{*}{ Location } & Lower rectum & 1907 & $23.1 \%$ & 481 & $19.5 \%$ & \multirow[t]{3}{*}{$<0.001$} \\
\hline & Middle rectum & 3566 & $43.1 \%$ & 996 & $40.3 \%$ & \\
\hline & Upper rectum & 2799 & $33.8 \%$ & 996 & $40.3 \%$ & \\
\hline \multirow[t]{3}{*}{ UICC stage } & I & 2728 & $33.0 \%$ & 930 & $37.6 \%$ & \multirow[t]{3}{*}{$<0.001$} \\
\hline & II & 2471 & $29.9 \%$ & 631 & $25.5 \%$ & \\
\hline & III & 3073 & $37.1 \%$ & 912 & $36.9 \%$ & \\
\hline \multirow[t]{2}{*}{ Grading } & $\mathrm{G} 1 / 2$ & 7055 & $85.3 \%$ & 2135 & $86.3 \%$ & \multirow[t]{2}{*}{0.195} \\
\hline & $\mathrm{G} 3 / 4$ & 1217 & $14.7 \%$ & 338 & $13.7 \%$ & \\
\hline \multirow[t]{2}{*}{ Perioperative chemoradiotherapy } & Yes & 3427 & $41.4 \%$ & 922 & $37.3 \%$ & \\
\hline & No & 4845 & $58.6 \%$ & 1551 & $62.7 \%$ & $<0.001$ \\
\hline
\end{tabular}

cases, the surgical approach was unknown. These patients were excluded from further analyses (Fig. 1).

The final dataset included 10,745 patients. The observed laparoscopy rate was $23.0 \%$ on average, with the rate increasing over time from $13.7 \%$ in 2005 to $34.1 \%$ in 2014 . Laparoscopy patients were more often female (39.0 vs. $33.7 \%$ ) and younger (mean age 64.2 vs. 65.8 years; median age 65.5 vs. 67.5 years). Laparoscopically resected tumors were more frequently located in the upper third of the rectum (12-16 cm from anal verge) and were more often diagnosed as UICC stage I. UICC stage III was distributed almost equally between the open and laparoscopic treatment groups (laparoscopy 36.9 vs. open surgery $37.1 \%$; Table 1 ).

The overall mortality rate 30 days after surgery was $1.4 \%$. Among patients aged 59 years or younger, $0.4 \%$ had died, compared to $2.3 \%$ among the septuagenarians. Uni- and multivariable regression analysis of 30-day postoperative mortality revealed advantages for laparoscopically treated patients, although the significance level was not reached (in the highest age group, it was missed only slightly: odds ratio, OR 0.559 ; 95\% confidence interval, 95\% CI 0.296-1.058; Fig. $2 \mathrm{a}-\mathrm{f})$.
Fig. 1 Flowchart of study patient selection

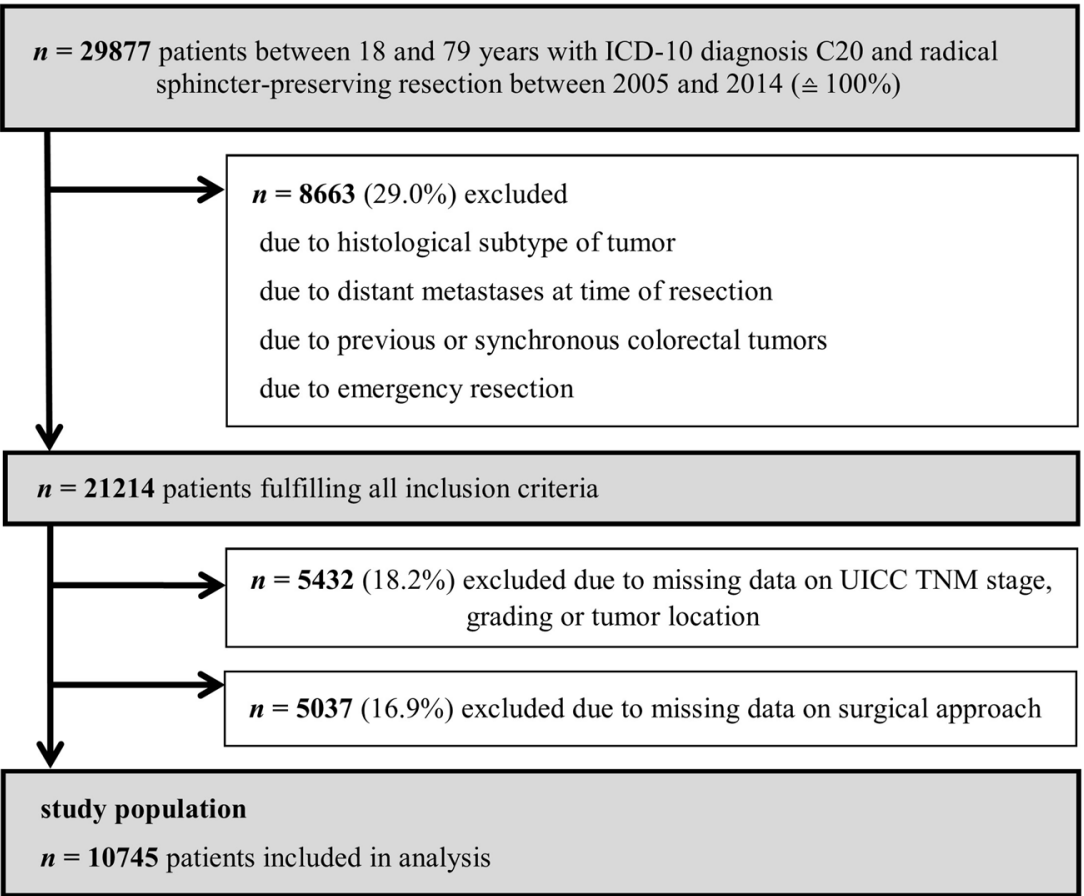




\begin{tabular}{|c|c|c|c|c|}
\hline a & & $\mathrm{OR}$ & $\mathrm{CI}$ & $p$-value \\
\hline Open & & 1 & & \\
\hline Laparoscopi & & 0.473 & $0.105-2.139$ & 0.331 \\
\hline 0 & 0.5 & 1 & 1.5 & 2.5 \\
\hline b & & OR & $\mathrm{CI}$ & $p$-value \\
\hline Open & & 1 & & \\
\hline Laparoscopi & & 0.524 & $0.115-2.387$ & 0.404 \\
\hline 0 & 0.5 & 1 & 1.5 & 2.5 \\
\hline c & & $\mathrm{OR}$ & $\mathrm{CI}$ & $p$-value \\
\hline Open & & 1 & & \\
\hline Laparoscopi & & 0.715 & $0.315-1.622$ & 0.422 \\
\hline 0.2 & 0.6 & 1 & 1.4 & 1.8 \\
\hline d & & $\mathrm{OR}$ & $\mathrm{CI}$ & $p$-value \\
\hline Open & & 1 & & \\
\hline Laparoscopi & & 0.686 & $0.301-1.567$ & 0.372 \\
\hline 0.2 & 0.6 & 1 & 1.4 & 1.8 \\
\hline e & & OR & $\mathrm{CI}$ & $p$-value \\
\hline Open & & 1 & & \\
\hline Laparoscopi & & 0.537 & $0.285-1.012$ & 0.054 \\
\hline 0.2 & 0.4 & 0.6 & 1 & 1.4 \\
\hline$f$ & & $\mathrm{OR}$ & $\mathrm{CI}$ & $p$-value \\
\hline Open & & 1 & & \\
\hline Laparoscopi & & 0.559 & $0.296-1.058$ & 0.074 \\
\hline 0.2 & 0.4 & 0.6 & 0.8 & 1.2 \\
\hline
\end{tabular}

In the subsequent analyses of long-term survival, the effect of perioperative mortality has been nullified by exclusion of patients with a survival or observation time of less than 31 days.

In Kaplan-Meier analysis, patients treated with minimally invasive surgery had a significant survival advantage, regardless of age. Among septuagenarians, $74.9 \%$ of laparoscopic and $69.5 \%$ of open surgery patients survived the first 5 postoperative years $(p=0.009)$. A comparable advantage for laparoscopy can be seen in the middle and youngest age groups. After adjustment for sex, tumor location, UICC stage, grading,
Fig. 2 Postoperative mortality (30 days). OR odds ratio, CI two-sided 95\% confidence interval. Logistic regression analysis comparing 30-day postoperative mortality rates open vs. laparoscopic surgery; reference: open approach. a Univariable logistic regression analysis on patients < 60 years. b Multivariable logistic regression analysis on patients < 60 years; adjustment for sex, location, TNM stage, grading, and perioperative therapy; reference: open approach. c Univariable logistic regression analysis on patients 60-69 years. $\mathbf{d}$ Multivariable logistic regression analysis on patients 60-69 years; adjustment for sex, location, TNM stage, grading, and perioperative therapy; reference: open approach. e Univariable logistic regression analysis on patients $70-79$ years. f Multivariable logistic regression analysis on patients $70-79$ years; adjustment for sex, location, TNM stage, grading, and perioperative therapy; reference: open approach

and perioperative therapy, the superiority of laparoscopy remains significant in all age groups (Fig. 3a-f).

Taking into account the baseline mortality of the German population, the 5-year relative survival rate of laparoscopic patients aged younger than 50 years was $93.2 \%$, compared to $89.0 \%$ in the open resection group $(p=0.024)$. Laparoscopy also turned out to be superior in the other age groups (60-69 years 92.4 vs. $87.2 \%, p<0.001 ; 70-79$ years 87.5 vs. $80.7 \%, p=0.012$ ).

A similar situation can be observed for 5-year recurrencefree survival. While recurrence-free survival rates are generally indirectly proportional to age, laparoscopy turned out to be the significantly superior approach in all analyzed strata. For example, among patients aged 60 to 69 years, 5 years after surgery, $78.5 \%$ of laparoscopic compared to $72.4 \%$ of open surgery patients were still alive and had not yet suffered from a recurrence $(p=0.001)$. Upon performing a multivariable Cox regression analysis, the situation changes slightly: an agedependent gradient can now be seen. With a HR of 0.703 (95\% CI 0.578-0.855), the greatest advantage for the minimally invasive approach was achieved in the youngest age group. Among septuagenarians, no significant advantage could be observed (HR $0.923,95 \%$ CI $0.798-1.066$; Fig. 4a-f).

Finally, a sensitivity analysis was conducted to quantify bias due to exclusion of patients with missing data. In terms of 30-day postoperative mortality, included patients did not have a significant advantage over excluded patients $(<$ 60 years OR $0.96, p=0.401 ; 60-69$ years OR $0.95, p=$ $0.069 ; 70-79$ years OR $0.98, p=0.214$ ). Looking at 5-year overall survival rates, included patients did have a significantly superior survival rate compared to patients excluded due to missing data $(79.5$ vs. $78.1 \%, p=0.017)$. However, the absolute difference in survival rates was only $0.6 \%$.

\section{Discussion}

The present study investigates the question of whether laparoscopy and laparotomy are equally suitable in all age groups. 

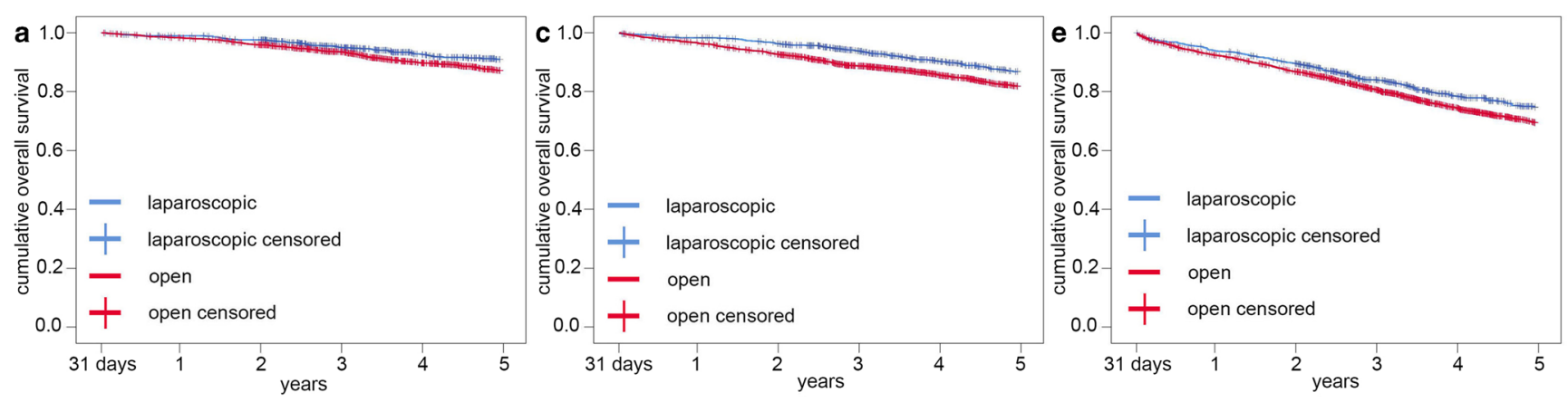

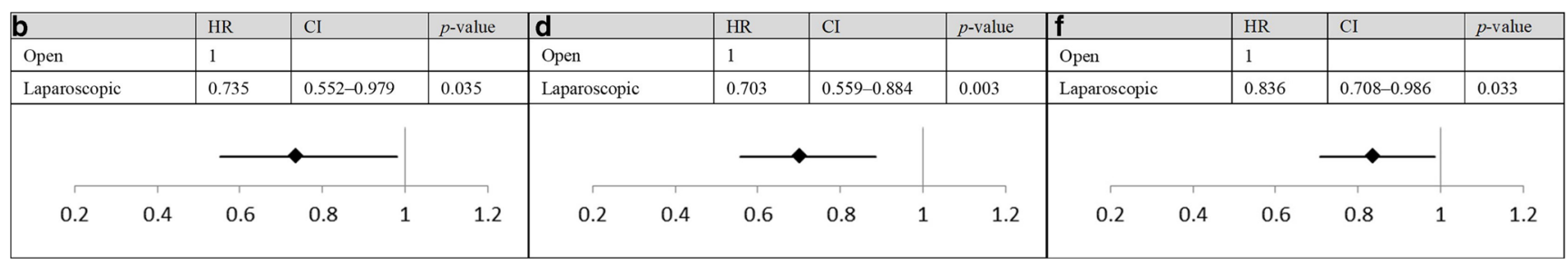

Fig. 3 Overall survival after perioperative period ( 31 days-5 years). HR hazard ratio, CI two-sided 95\% confidence interval. a Kaplan-Meier analysis on patients $<60$ years: 5 -year cumulative overall survival rate open vs. laparoscopic surgery: 87.2 vs. $91.0 \%, p=0.011$. b Multivariable Cox regression analysis on patients $<60$ years, adjustment for sex, location, TNM stage, grading, and perioperative therapy; reference: open approach. c Kaplan-Meier analysis on patients 60-69 years: 5-year cumulative overall survival rate open vs. laparoscopic: 81.9 vs. $86.8 \%, p=$
0.001. d Multivariable Cox regression analysis on patients 60-69 years, adjustment for sex, location, TNM stage, grading, and perioperative therapy; reference: open approach. e Kaplan-Meier analysis on patients 70 79 years: 5-year cumulative overall survival rate open vs. laparoscopic: 69.5 vs. $74.9 \%, p=0.009$. f Multivariable Cox regression analysis on patients 70-79 years, adjustment for sex, location, TNM stage, grading, and perioperative therapy; reference: open approach

terms of 5-year overall survival, the superiority of laparoscopy remains significant in all age-stratified subgroups even after adjustment for relevant covariables. The minimally invasive approach is also followed by lower recurrence rates.
The analyses on 10,745 patients from a German cancer registry grid showed nonsignificant advantages for laparoscopically treated patients concerning the 30-day postoperative mortality with similar results in all age groups. In
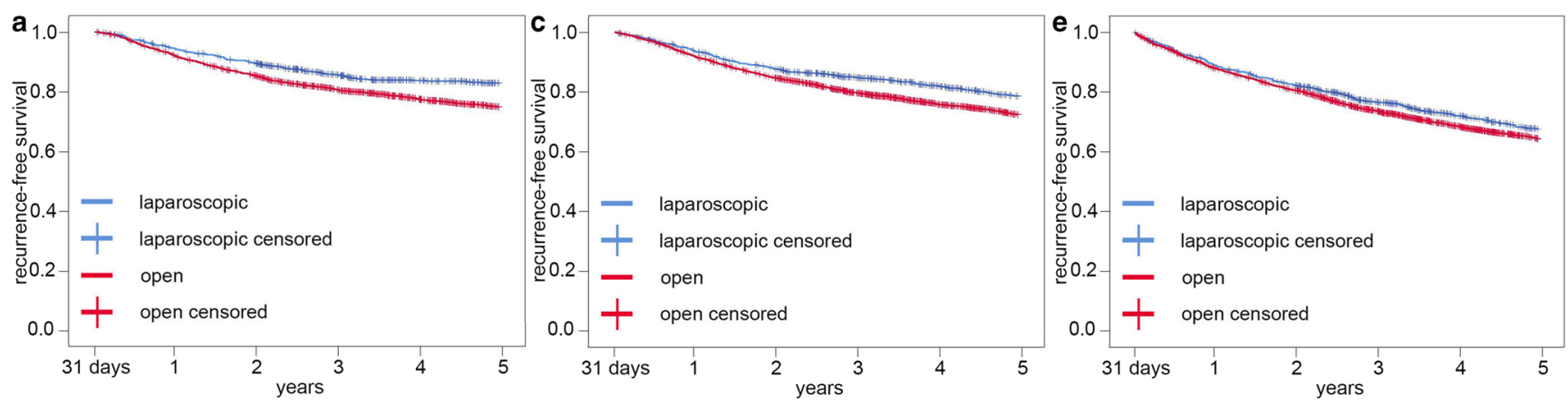

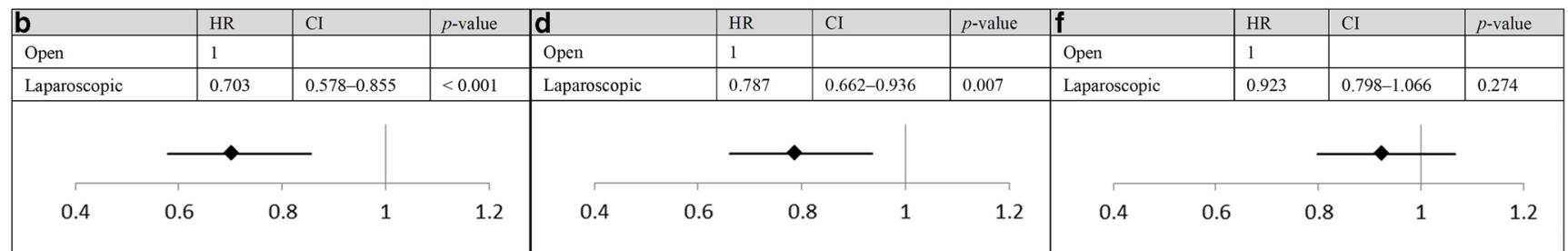

Fig. 4 Recurrence-free survival after perioperative period (31 days5 years). HR hazard ratio, CI two-sided $95 \%$ confidence interval. a Kaplan-Meier analysis on patients $<60$ years: 5-year cumulative recurrence-free survival rate open vs. laparoscopic: 75.1 vs. $82.9 \%$, $p<0.001$. b Multivariable Cox regression analysis on patients $<60$ years, adjustment for sex, location, TNM stage, grading, and perioperative therapy; reference: open approach. c Kaplan-Meier analysis on patients 60 69 years: 5-year cumulative recurrence-free survival rate open vs. laparoscopic: 72.4 vs. $78.5 \%, p=0.001$. d Multivariable Cox regression analysis on patients 60-69 years, adjustment for sex, location, TNM stage, grading, and perioperative therapy; reference: open approach. e Kaplan-Meier analysis on patients 70-79 years: 5-year cumulative recurrence-free survival rate open vs. laparoscopic: 64.4 vs. $67.6 \%, p=$ 0.089. f Multivariable Cox regression analysis on patients 70-79 years, adjustment for sex, location, TNM stage, grading, and perioperative therapy; reference: open approach 
Concerning 5-year recurrence-free survival, younger patients seem to benefit more from laparoscopy.

These results give valuable insight into the daily clinical practice of rectal cancer surgery, since data comparing longterm results after laparoscopic vs. open approaches are scarce. It is only 3 years ago, that one of the first high-quality randomized controlled trials (RCTs) on the topic, the international COLOR II trial, was published [3]. These authors demonstrated the general oncologic safety of the minimally invasive approach. The validity of these positive results in daily clinical practice was confirmed by analyzing a representative cohort of approximately 1500 patients from southern Germany [4]. However, no two patients are exactly alike, and only individualized treatment will result in optimal outcomes, hence the need for more detailed analyses.

When selecting the appropriate therapeutic pathway to treat cancer, many aspects must be considered. Age is inevitably one of these aspects. Several studies have shown that there is a strong association between age and the prevalence of comorbidities $[26,27]$. Therefore, there is a consensus that studies comparing treatment options such as different surgical approaches must regard age as a potential confounder, at least if the age distribution differs between treatment groups.

In most observational studies on the topic, laparoscopically treated patients have tended to be younger. For example, Nussbaum et al. used a large cancer registry from the USA and examined approximately 19,000 patients with low anterior rectum resection due to carcinoma [28]. Patients receiving minimally invasive surgery were significantly younger by 1 year. In 2015, Yeo et al. performed a large multicenter trial and found laparoscopic surgery patients to be, on average, 2.5 years younger [29]. In the publication of Draeger et al., laparoscopy patients were younger by 2.9 years on average, with age groups significantly differently distributed among the comparison groups $(p<0.001)$ [4]. Kolfschoten et al. also identified lower age as a relevant predictor for the laparoscopic approach [30]. Even in the randomized COLOR II trial, an age difference of 1 year between groups could be observed, while in this case, laparoscopic patients had the higher mean age, with 66.8 years [7]. Age obviously plays an important role in the selection of surgical approach.

This raises the question of whether laparoscopy and laparotomy are equally suitable in all age groups. A large study population is crucial for representative and statistically stable results at the subgroup level. Unfortunately, the problem of enrolling a sufficiently large number of participants is a common issue in RCTs. COLOR II, for instance, although currently the largest clinical trial on rectal cancer surgery, included only 1044 patients [3]. More substantial caseloads are reached in some registry-based studies, such as that of Nussbaum et al. [28]. However, most of these investigations suffer from a different limitation: in the absence of data on long-term survival, analyses have to be restricted to perioperative outcomes. To the best of our knowledge, the present study is the first with both a substantial caseload and true long-term follow-up. The age-stratified comparison of laparoscopic and open surgery for colorectal cancer resection performed herein permits assessment of potential effect modification of survival outcomes for the first time.

Some limitations must be considered when interpreting the results presented in this study. Unfortunately, information on nononcologic comorbidities is lacking, since there is no consensus between the participating cancer registries on the issue and, therefore, systematic documentation of American Society of Anesthesiologists (ASA) or a comorbidity score does not take place. However, there is evidence that stratifying by age, as it was done in this study, may partly account for this shortage: older patients tend to suffer from more potentially life-threatening illnesses than younger patients [26]. According to a survey by the Dutch cancer registry on colorectal cancer patients, there is a significant association between age and the number of comorbidities [27]. Notwithstanding, a future systematic documentation of ASA or a different comorbidity score is desirable to enable more accurate risk adjustment.

As stated above, this survey aims to paint a holistic picture of national rectal cancer care. Therefore, many regional cancer registries were encouraged to provide their data. However, some of these institutions are better established than others, leading to a somewhat inhomogeneous data quality level. If information gaps could not be filled, patients had to be excluded to match mandatory statistical standards. Therefore, a sensitivity analysis was conducted and could show that the necessary exclusion process only introduced a small amount of bias into the analysis of long-term survival, while results on short-term survival were not influenced significantly at all. Thus, all presented findings can be regarded as stable.

Concerning short-term outcomes, laparoscopic surgery patients in this study had a lower postoperative mortality rate in all age groups. However, the effect size was only moderate and the significance level was not reached in any age group. Extensive literature research revealed that Landi et al. also analyzed death within 30 days after surgery and found a significantly lower mortality rate in the laparoscopic than the open surgery group for patients under 80 years $(0$ vs. $4.6 \%, p=0.049$ ) [31]. A possible reason for the advantage of the minimally invasive surgical approach could be the lower postoperative complication rate. For example, Kolfschoten et al. and Mroczkowski et al. observed a higher number of complications after the conventional approach $[6$, 30]. McKay et al. divided their collective into patients under and over 70 years and analyzed the postoperative complication rate. In both age groups, more complications occurred after open surgery. Additionally, the complication rate was higher among patients aged over 70 years, both in the open 
and in the laparoscopic group [32]. Taking all these studies into account, laparoscopy indeed seems to be the superior surgical approach in terms of short-term outcomes, but age is not an effect modifier.

A significant advantage of laparoscopy could again be observed for overall survival in all age groups 5 years after surgery. Regarding recurrence-free survival, rates were higher in the laparoscopic group, although the significance level was no longer reached in the oldest group. Taking a closer look at the actual effect sizes after adjustment for confounders, an agedependent gradient can be seen: With 0.703 , the HR for laparoscopy is lowest in the youngest age group, grows to 0.787 in patients between 60 and 69 years, and is highest among septuagenarians ( $H R=0.923)$. In the long term, young people obviously benefit most from minimally invasive surgery, while survival and recurrence patterns in older patients seem to depend less on the surgical approach. Future research is indispensable to further investigate the reasons for this observation.

All results of this study are based on 10,745 patients from 30 regional cancer registries covering approximately one quarter of the German population and can be regarded as representative. Even considering all limitations, the presented findings are statistically stable over all investigated age groups. Moreover, the application of multivariable analyses and relative survival models generated adjusted results going beyond mere observation. These can be used for direct comparison with patient samples from other regions. Thus, future research on this topic shall be encouraged.

\section{Conclusion}

In terms of postoperative survival, laparoscopy is at least equivalent to open surgery, with similar results in all age groups. Laparoscopy is also followed by better long-term survival and lower recurrence rates. Particularly, younger patients seem to benefit more from the minimally invasive approach. Increased use of laparoscopy for rectal cancer should be considered in this group.

Acknowledgments The authors thank all participating registries (Augsburg, Berlin, Dresden, Stuttgart OSP, Zwickau, Chemnitz, Dessau, Koblenz, Halle, Leipzig, Bayreuth, Göppingen OSP, Erfurt, Westfalen-Lippe, Magdeburg, Erlangen-Nürnberg, Gera, Nordhausen, Jena, Brandenburg, Suhl, Regensburg, Ulm-CCC, Reutlingen, Ravensburg, Wiesbaden, Hamburg, Hanau Klinikum, Hannover, and Mecklenburg-Vorpommern) for their cooperation. We also would like to thank Dr. Hagen Barlag $(\dagger)$ for preparing the dataset.

\section{Compliance with ethical standards}

Conflict of interest The authors declare that they have no conflict of interest.
Research involving human and animal participants This article does not contain any studies with human participants or animals performed by any of the authors.

Open Access This article is distributed under the terms of the Creative Commons Attribution 4.0 International License (http:// creativecommons.org/licenses/by/4.0/), which permits unrestricted use, distribution, and reproduction in any medium, provided you give appropriate credit to the original author(s) and the source, provide a link to the Creative Commons license, and indicate if changes were made.

Publisher's note Springer Nature remains neutral with regard to jurisdictional claims in published maps and institutional affiliations.

\section{References}

1. Robert Koch-Institut (2016) Bericht zum Krebsgeschehen in Deutschland 2016. https://doi.org/10.17886/rkipubl-2016-014

2. Stewart BW, Wild CP (2014) World Cancer Report 2014, OnlineAusg. EBL-Schweitzer. International Agency for Research on Cancer/World Health Organization, Lyon

3. Bonjer HJ, Deijen CL, Abis GA, Cuesta MA, van der Pas M, de Lange-de Klerk ES, Lacy AM, Bemelman WA, Andersson J, Angenete E, Rosenberg J, Fuerst A, Haglind E, COLOR II Study Group (2015) A randomized trial of laparoscopic versus open surgery for rectal cancer. N Engl J Med 372(14):1324-1332. https:// doi.org/10.1056/NEJMoa1414882

4. Draeger T, Völkel V, Gerken M, Klinkhammer-Schalke M, Fürst A (2018) Long-term oncologic outcomes after laparoscopic versus open rectal cancer resection: a high-quality population-based analysis in a Southern German district. Surg Endosc 32:4096-4104. https://doi.org/10.1007/s00464-018-6148-6

5. Kuhry E, Schwenk WF, Gaupset R et al. (2008) Long-term results of laparoscopic colorectal cancer resection. Cochrane Database Syst Rev(2): CD003432. https://doi.org/10.1002/14651858. CD003432.pub2

6. Mroczkowski P, Hac S, Smith B, Schmidt U, Lippert H, Kube R (2012) Laparoscopy in the surgical treatment of rectal cancer in Germany 2000-2009. Color Dis 14(12):1473-1478. https://doi. org $/ 10.1111 / j .1463-1318.2012 .03058 . x$

7. van der Pas MH, Haglind E, Cuesta MA et al (2013) Laparoscopic versus open surgery for rectal cancer (COLOR II): short-term outcomes of a randomised, phase 3 trial. Lancet Oncol 14(3):210-218. https://doi.org/10.1016/S1470-2045(13)70016-0

8. Spinelli A, D'Hoore A, Panis Y, Bemelman WA, Jayne DG, Fürst A (2017) Critical appraisal of two randomized clinical trials on pathologic outcomes. coloproctology 39(4):277. https://doi.org/10. 1007/s00053-017-0178-8

9. Steele SR, Park GE, Johnson EK, Martin MJ, Stojadinovic A, Maykel JA, Causey MW (2014) The impact of age on colorectal cancer incidence, treatment, and outcomes in an equal-access health care system. Dis Colon Rectum 57(3):303-310. https://doi.org/10. 1097/DCR.0b013e3182a586e7

10. Leitlinienprogramm Onkologie (Deutsche Krebsgesellschaft, Deutsche Krebshilfe, AWMF): S3-Leitlinie Kolorektales Karzinom, Langversion 1.1, 2014 , AWM F Registrierungsnummer: 021-007OL, http://leitlinienprogrammonkologie.de/Leitlinien.7.0.html. Accessed 12 Feb 2019

11. Wesselmann S, Follmann M (2011) Leitlinien und Zertifizierung im DKG-Qualitätszirkel. Forum 109(26):15-17

12. Völkel V, Draeger T, Gerken M et al. (2018) Langzeitüberleben von Patienten mit Kolon- und Rektumkarzinomen: Ein Vergleich von Darmkrebszentren und nicht zertifizierten Krankenhäusern (LongTerm Survival of Patients with Colon and Rectum Carcinomas: Is 
There a Difference Between Cancer Centers and Non-Certified Hospitals?). Gesundheitswesen. https://doi.org/10.1055/a-05913827

13. Arbeitsgemeinschaft Deutscher Tumorzentren e.V. ADT - für Qualitätssicherung in der Onkologie. https://www.tumorzentren. de/. Accessed 12 Feb 2019

14. Deutsches Institut für Medizinische Dokumentation und Information (DIMDI) im Auftrag des Bundesministeriums für Gesundheit (BMG) unter Beteiligung der Arbeitsgruppe ICD des Kuratoriums für Fragen der Klassifikation im Gesundheitswesen (KKG) (Hrsg.) (2017). ICD-10-GM Version 2017. Systematisches Verzeichnis Internationale statistische Klassifikation der Krankheiten und verwandter Gesundheitsprobleme, 10. Revision - German Modification. https://www.dimdi.de/dynamic/de/ klassifikationen/downloads/?dir=icd-10-gm/version 2017. Accessed 12 Feb 2019

15. Majek O, Gondos A, Jansen L, Emrich K, Holleczek B, Katalinic A, Nennecke A, Eberle A, Brenner H, the GEKID Cancer Survival Working Group (2013) Sex differences in colorectal cancer survival: population-based analysis of 164,996 colorectal cancer patients in Germany. PLoS One 8(7):e68077. https://doi.org/10.1371/ journal.pone. 0068077

16. Silberfein EJ, Kattepogu KM, Hu C-Y, Skibber JM, RodriguezBigas MA, Feig B, Das P, Krishnan S, Crane C, Kopetz S, Eng C, Chang GJ (2010) Long-term survival and recurrence outcomes following surgery for distal rectal cancer. Ann Surg Oncol 17(11): 2863-2869. https://doi.org/10.1245/s10434-010-1119-8

17. Konn M, Morita T, Hada R, Yamanaka Y, Sasaki M, Munakata H, Suzuki H, Inoue S, Endoh M, Sugiyama Y, Ono K (1993) Survival and recurrence after low anterior resection and abdominoperineal resection for rectal cancer: the results of a long-term study with a review of the literature. Surg Today 23(1):21-30

18. Cancer Research UK (2011) Bowel cancer incidence statistics. http://www.cancerresearchuk.org/health-professional/cancerstatistics/statistics-by-cancer-type/bowel-cancer/incidence\# heading-Two. Accessed 12 Feb 2019

19. Gunderson LL, Sargent DJ, Tepper JE, Wolmark N, O'Connell MJ, Begovic M, Allmer C, Colangelo L, Smalley SR, Haller DG, Martenson JA, Mayer RJ, Rich TA, Ajani JA, MacDonald JS, Willett CG, Goldberg RM (2004) Impact of T and N stage and treatment on survival and relapse in adjuvant rectal cancer: a pooled analysis. J Clin Oncol 22(10):1785-1796. https://doi.org/10.1200/ JCO.2004.08.173

20. Wu Y, Liu H, Du XL et al (2017) Impact of neoadjuvant and adjuvant radiotherapy on disease-specific survival in patients with stages II-IV rectal cancer. Oncotarget 8(63):106913-106925. https://doi.org/10.18632/oncotarget.22460

21. Mokdad A, Huerta S, Minter RM et al (2017) Effect of adjuvant chemotherapy following pathologic complete response on long- term survival in rectal cancer: a propensity score matched analysis. JCO 35(4_suppl):717. https://doi.org/10.1200/JCO.2017.35.4 suppl.717

22. Cox D (1972) Regression models and life-tables. Journal of the Royal Statistical Society Series B 34(2):187-220

23. Pohar M, Stare J (2006) Relative survival analysis in R. Comput Methods Prog Biomed 81(3):272-278. https://doi.org/10.1016/j. cmpb.2006.01.004

24. Human Mortality Database. University of California, Berkeley (USA), and Max Planck Institute for Demographic Research (Germany). Available at www.mortality.org or www. humanmortality.de. Accessed 02 Sep 2017

25. von Elm E, Altman DG, Egger M, Pocock SJ, Gøtzsche PC, Vandenbroucke JP (2007) The Strengthening the Reporting of Observational Studies in Epidemiology (STROBE) statement: guidelines for reporting observational studies. Lancet 370(9596): 1453-1457. https://doi.org/10.1016/S0140-6736(07)61602-X

26. Piccirillo JF, Vlahiotis A, Barrett LB, Flood KL, Spitznagel EL, Steyerberg EW (2008) The changing prevalence of comorbidity across the age spectrum. Crit Rev Oncol Hematol 67(2):124-132. https://doi.org/10.1016/j.critrevonc.2008.01.013

27. van Leersum NJ, Janssen-Heijnen MLG, Wouters MWJM, Rutten HJT, Coebergh JW, Tollenaar RAEM, Lemmens VEPP (2013) Increasing prevalence of comorbidity in patients with colorectal cancer in the South of the Netherlands 1995-2010. Int J Cancer 132(9):2157-2163. https://doi.org/10.1002/ijc.27871

28. Nussbaum DP, Speicher PJ, Ganapathi AM, Englum BR, Keenan JE, Mantyh CR, Migaly J (2015) Laparoscopic versus open low anterior resection for rectal cancer: results from the national cancer data base. J Gastrointest Surg 19(1):124-132. https://doi.org/10. 1007/s11605-014-2614-1

29. Yeo HL, Yeo HL, Abelson JS et al (2016) Minimally invasive surgery and sphincter preservation in rectal cancer. J Surg Res 202(2):299-307. https://doi.org/10.1016/j.jss.2016.01.010

30. Kolfschoten NE, van Leersum NJ, Gooiker GA, van de Mheen PJM, Eddes EH, Kievit J, Brand R, Tanis PJ, Bemelman WA, Tollenaar RAEM, Meijerink J, Wouters MWJM (2013) Successful and safe introduction of laparoscopic colorectal cancer surgery in Dutch hospitals. Ann Surg 257(5):916-921. https://doi. org/10.1097/SLA.0b013e31825d0f37

31. Landi F, Vallribera F, Rivera JP et al (2015) Morbidity after laparoscopic and open rectal cancer surgery: a comparative analysis of morbidity in octogenarians and younger patients. Color Dis 18(5): 459-467. https://doi.org/10.1111/codi.13136

32. McKay GD, Morgan MJ, S-KC W et al (2012) Improved short-term outcomes of laparoscopic versus open resection for colon and rectal cancer in an area health service: a multicenter study. Dis Colon Rectum 55(1):42-50. https://doi.org/10.1097/DCR. 0b013e318239341f 